Connotas. Revista de crítica y teoría literarias 
CONNOTAS. REVISTA DE CRÍTICA Y TEORÍA LITERARIAS. Enero - diciembre 2013, es una publicación anual editada por la Universidad de Sonora, a través de la División de Humanidades y Bellas Artes, en el Departamento de Letras y Lingüística. Blvd. Luis Encinas y Blvd. Rosales s/n, Col. Centro, C.P. 83000, Hermosillo Sonora; Tel. (662) 2592 136, (662) 2592 157, <www.uson.mx>, <http://www.connotas.uson.mx, connotas@capomo.uson.mx>. Editor responsable: Rosario Fortino Corral Rodríguez. Reservas de Derechos al Uso Exclusivo núm. 04-2006-020714184900-102. ISSN: 18706630; ambos otorgados por el Instituto Nacional del Derecho de Autor. Licitud de Título núm. 13434 y de Contenido núm. 11007, otorgados por la Comisión Calificadora de Publicaciones y Revistas Ilustradas de la Secretaría de Gobernación. Este libro se publicó con el apoyo del Programa Integral de Fortalecimiento Institucional C/PIFI 2013-12934

Se autoriza la reproducción total o parcial de los contenidos de la presente publicación, siempre y cuando se acredite adecuadamente el origen de los mismos.

Datos de contacto para la publicación: División de Humanidades y Bellas Artes, Departamento de Letras y Lingüística; Apartado Postal 793, Col. Centro, C.P. 83000, Hermosillo, Sonora, México. Tels.: (662) 259-21-87, Tel-fax 212-55-29. Correo electrónico: connotas@capomo.uson.mx Página web: http://www.connotas.uson.mx 


\section{Connotas. Revista de crítica y teoría literarias}

Núm. 13, año 2013

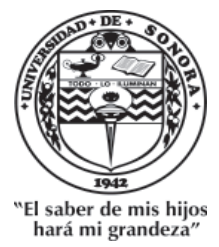


UNIVERSIDAD DE SONORA

RECTOR

Heriberto Grijalva Monteverde

VICERRECTORA

Arminda Guadalupe García de León Peñúñuri

Secretario General Académico

Enrique Fernando Velázquez Contreras

División de Humanidades y Bellas Artes

María Rita Plancarte Martínez

Departamento de Letras y LingÜística

Ana Bertha de la Vara Estrada

César Avilés Icedo

Rosa María Burrola Encinas

Fortino Corral Rodríguez

Leticia Martínez Figueroa

Jesús Abad Navarro Gálvez

Gabriel Osuna Osuna

María Rita Plancarte Martínez

DiRECTOR

Fortino Corral Rodríguez

Giuseppe Bellini

Consejo InTERnacional

Universidad de Milán

Carlos Pacheco

Luis Beltrán Almería

Universidad Simón Bolivar

Universidad de Zaragoza

Rafael Olea Franco

Helena Beristáin

El Colegio de México

Joan Oleza Simó

Universidad Nacional Autónoma de México

Universidad de Valencia

Raúl Bueno-Chávez

Dartmouth College

Julio Ortega

Evodio Escalante

Brown University

Luz Aurora Pimentel

Universidad Autónoma Metropolitana

Universidad Nacional Autónoma de México

Beatriz González-Stephan

Susana Reisz

Rice University

Aníbal González

The City University of New York.

José Carlos Rovira

Universidad de Alicante

Yale University

Aurelio González Pérez

Charles Tatum

El Colegio de México

Yvette Jiménez de Báez

The University of Arizona

Jorge Urrutia

El Colegio de México

Universidad Carlos III de Madrid

Nelson Osorio Tejeda

Universidad de Santiago de Chile

Emil Volek

Arizona State University 


\section{Índice}

\section{Artículos}

Una hermenéutica analógica para la literatura

Mauricio Beuchot Puente

La obra de Jorge Luis Borges durante la década de 1930: estudio de algunos elementos para la conformación de su poética en Discusión (1932)

Daniel Zavala Medina

Metáforas de la locura y la muerte en "Río subterráneo" de Inés Arredondo

Gabriel Osuna Osuna

La alteridad como vector de la construcción del yo: La muerte me da de Cristina Rivera Garza y El Gran Vidrio de Mario Bellatin Véronique Pitois Pallares

Uno soñaba que era rey de Enrique Serna: un espacio de contradicción Claudia Gidi

Una angustia compartida. Análisis de la voz narrativa en Mi hermano Carlos de Jorge López Páez

Jorge Antonio Muñoz Figueroa

De Los perros románticos y otros poemas de Roberto Bolaño Marina Martínez Andrade 
Las novelas del Crack, multiplicidad y superposición de mundos Ramón Alvarado Ruiz

La construcción del “otro" en la Relación de la jornada de Cíbola de Pedro Castañeda de Nájera

Guillermo Martínez Sotelo

Destino e historia en Margarita, está linda la mar de Sergio Ramírez

María Rita Plancarte Martínez

\section{Notas}

Identidad negada y mundo al revés en Santa María del Circo de David Toscana

César Avilés Icedo y María Elena González Borgaro 203

"El buen ejemplo" de Vicente Riva Palacio: la historia de un cuento

Marco Antonio Chavarín González

Organización descriptiva en Catarina de San Juan, princesa de la India y visionaria de Puebla

Silvia Guadalupe Alarcón Sánchez

Genealogías en Todo aqui es polvo de Esther Seligson. Lectura a partir de los epígrafes

Luz Elena Zamudio Rodríguez

\section{Reseñas}

Martha Elena Munguía Zatarain. La risa en la literatura mexicana (apuntes de poética)

Silvia Alicia Manzanilla Sosa 
Véronique Pitois-Pallares. El arte del fragmento: El Gran Vidrio de Mario Bellatin

Julio César Zárate Ramírez 255

Nicolás Kanellos. Hispanic Immigrant Literature: El sueño del retorno Josué Gutiérrez González

Dante Salgado. Brevísima relación de la idea de amor en Occidente Diana Vanessa Geraldo Camacho 271

Mara L. García. Paco Yunque: una mirada crítica Juan Paredes Carbonell 279

Abstracts 283

Résumés

Normas editoriales 



\title{
Metáforas de la locura y la muerte en "Río subterráneo" de Inés Arredondo
}

\author{
Gabriel Osuna Osuna*
}

Resumen:

En el cuento "Río subterráneo" Inés Arredondo emprende una tarea singular: crea una voz narrativa femenina que presenta una poética en donde la memoria juega un papel fundamental a través de la palabra escrita. El objetivo de este artículo es determinar y analizar cómo en este cuento se crea un universo específico en el cual se estructuran una serie de imágenes poéticas que terminan construyendo ideas precisas y constantes acerca de la locura y su relación con la muerte. De esta manera, la enunciación de la voz femenina funciona como un medio que construye, mediante el recuerdo y la reproducción de otras voces familiares, un conjunto de metáforas que intento describir con mayor detalle para contribuir en los estudios de interpretación, siempre necesarios, de la compleja obra cuentística de Arredondo.

Palabras clave:

Literatura escrita por mujeres, confesión, locura y representación, Generación de Medio Siglo, Escritoras Mexicanas.

En el cuento "Río subterráneo" (1979), publicado en el volumen que lleva el mismo título, Inés Arredondo emprende una tarea singular: crea una voz narrativa que presenta una poética en donde la

\footnotetext{
${ }^{*}$ Universidad de Sonora.
} 
memoria juega un papel fundamental a través de la palabra escrita. El objetivo de este escrito es determinar y analizar cómo en este cuento se crea un universo específico en el cual se estructuran una serie de imágenes poéticas que terminan construyendo ideas precisas y constantes acerca de la locura y la muerte. De esta manera, la enunciación de la vOz narrativa funciona como un medio que construye, mediante el recuerdo y la reproducción de otras voces familiares, un conjunto de metáforas que intento describir con mayor detalle para contribuir en los estudios de interpretación, siempre necesarios, de la compleja obra cuentística de Arredondo.

Como sabemos, los temas de la locura ${ }^{1}$ y la muerte aparecen a lo largo de sus tres libros. Sobre todo la muerte como consecuencia de un complejo proceso de búsqueda de la plenitud a través del amor o la pureza, entendidos éstos como conceptos en los cuales encarna la complejidad del ser. Desde "Mariana" y "La Sunamita" en La señal (1965), pasando por los cuentos de Río subterráneo (1979), sin olvidar las interesantes exploraciones en su último volumen, Los espejos (1988), especialmente con "Sombra entre sombras", quizá el cuento de esta colección que más ha llamado la atención de la crítica. Lo anterior aparece de manera paradigmática en "Río subterráneo", probablemente uno de sus cuentos más complejos, pues es ahí donde, como en "Mariana", se encuentran unidos estos dos aspectos para dar significación y coherencia a una escritura particular, cuyas características formales y temáticas guían hacia una lectura que consideramos necesario explorar. ${ }^{3}$

${ }^{1}$ RAE: s.v. "locura". f. Privación del juicio o del uso de la razón. Referencias: Michel Foucault, Historia de la locura en la época clásica. Trad. de Juan José Utrilla. $2^{\mathrm{a}}$. Ed. México: FCE, 1986.

${ }^{2}$ De este volumen publiqué "La representación del Otro en 'Las palabras silenciosas"". Los divertimentos de las musas. Ensayos sobre escritoras mexicanas e hispanoamericana. Comp. y ed. Alma Leticia Martínez Figueroa (Hermosillo: Universidad de Sonora, 2009).

${ }^{3}$ Miguel Ángel Quemain publica en una entrevista a la autora titulada "El presentimiento de la verdad: Inés Arredondo" lo siguiente: 
Brevemente mencionaré algunos aspectos del cuento que aquí nos ocupa para recordar escenas, personajes e imágenes. En el inicio la narradora se presenta como testigo de la historia familiar, se dirige al sobrino y describe minuciosamente la casa en la que habita. En el patio central se encuentra una escalinata que sus hermanos Sergio y Sofía construyeron para llegar al margen del río. Hay un presente de la narración en el que la menor de cuatro hermanos da cuenta del estado actual de las propiedades y del devenir de cada uno de los miembros de la familia, sobre todo con el afán de explicar detalladamente su historia, para evitarse la posible visita del sobrino. Aparece de manera reiterada la frase "para que no tengas que venir...", o "para que no vengas", otorgando así al discurso un carácter explicativo que adquiere diferentes niveles de significación conforme se avanza en la lectura.

-[M.A.Q.] La pasión, el amor, el mal, la pureza, la prostitución son algunos de los temas en sus cuentos...

-[I.A.] Todos esos temas y además agrega uno que se te olvidaba, el de la muerte. El amor pasión muchas veces termina con la muerte, las pasiones exaltadas tienen esa marca, que, aunque no se produzca la muerte, está presente. Ahora, desde "El membrillo", mi primer cuento, hasta el último que cierra Los espejos, "Sombra entre sombras", lo que yo quería saber era qué era la pureza y qué la prostitución. Eso era una idea muy fuerte para mí; como dice Juan García Ponce, los verdaderos escritores, espero contarme entre ellos, viven siempre de obsesiones. En "El membrillo" uno de los personajes nos habla de la dificultad del mundo, de su imperfección, la inocencia se ha perdido, la pureza no, y en el último cuento invento cuanta barbaridad se puede inventar para llevar hasta sus últimos límites esta inquietud mía, para decir si ésta mujer es una prostituta, pero no, sigo con la duda, porque ella hace toda esa serie de aberraciones, o se presta a ellas, por amor, entonces yo todavía no me atrevo a juzgarla... Muchas veces encontramos la pureza en el corazón del perverso, de la perversión misma. Y, déjame decirte... a veces la locura es el espacio de la iluminación, ahí encontramos una intimidad que por lo general pasa desapercibida, pero también está ligada a esa idea del mal, que tanto nos atribuyen a Juan Vicente, a Salvador (Elizondo), a Juan (García Ponce) y a mí. No digo que el mal no exista en mi literatura, pero existe como el mecanismo más eficaz para devolverle la pureza a alguno de mis seres. <http:// www.literatura.bellasartes.gob.mx/acervos/index.php/catalogo-biobibliografico/ indice-onomastico/1702> 
Al mencionar que va a contar "la crueldad y la exquisitez de una vida de provincia" surgen algunas preguntas interesantes. ¿En qué consiste semejante crueldad?: probablemente tenga que ver con la forma en que describe el sufrimiento que conduce a la transformación psicótica de sus hermanos. La muerte, la angustia y sobre todo la espera ansiosa e incierta del "alarido" que comprueba la presencia definitiva de la enfermedad van a estar presentes desde que narra la historia del hermano mayor, Pablo, el padre del destinatario de la narración. Por otra parte, la exquisitez de esa vida de provincia puede relacionarse con la manera tan detallada, sutil y delicada en que vive la familia, a diferencia del resto de la gente del pueblo.

Al ver enloquecer a Pablo, Sofía le propuso a Sergio que construyera para "guardar el equilibrio". En realidad se trata de la necesidad (y después del hecho) de construir cuatro pabellones; uno para cada uno de ellos. Saben que la locura tarde o temprano llegará porque es una herencia familiar. Por eso, quien nos cuenta la historia dice: "Soy la guardiana de lo prohibido, de lo que no se explica, de lo que da vergüenza, y tengo que quedarme aquí para guardarlo, para que no salga, pero también para que exista. Para que exista y el equilibrio se haga. Para que no salga a dañar a los demás" (173). Hay que atenderla, tratarla, ponerle atención; no hay que ignorarla ni enviarla al sótano porque después se condensa y explota, para que no se despierte a la bestia.

El cuento se divide en siete fragmentos que aparecen según los recuerdos de la narradora: "En realidad todo comenzó antes de que yo pudiera entenderlo y te lo transmitiré de acuerdo con mis recuerdos, no con el tiempo ni lo razonamientos" (175). Después de presentar sus argumentos sobre los hechos y advertir al sobrino sobre aquellos aspectos que "sí los sabes, pero los sabes mal", narra cómo los síntomas de la enfermedad producen un extraño parecido entre los hermanos (Pablo y Sergio), que físicamente no se parecían, para después dedicarse a la descripción del episodio del saqueo de la casa y del pueblo por los revolucionarios.

Lo que también le enseñó Sofía fue el arte de narrar, medir y escoger cada una de las palabras que se tienen que usar al contar las vicisitudes de la enfermedad de Pablo, sobre todo en relación con el cuidado que ponía para elegir las palabras adecuadas para no aumen- 
tar la angustia de Sergio. Si ponemos atención, eso es exactamente lo que está haciendo con su sobrino quien ostenta la voz narrativa; la tía del destinatario, la tía narradora.

Del episodio de la noche del saqueo recuerda lo que hacían cuando el pueblo estaba sitiado: por ejemplo, estudiar Historia y tratar de comprender la enfermedad de Pablo. Alternadamente, Sofía describe la creciente angustia de Sergio y su genialidad creativa al concebir la escalinata, con los cuartos construidos a los costados de una explanada, que sorprendía a todos los visitantes. Es un texto multidimensional porque al utilizar el recurso del guión de diálogo aparecen las palabras de Sofía. Después, utiliza el espacio en blanco que divide un fragmento de otro, y continúa, ahora, en un texto diferente, entrecomillado, la reacción de ella, ante el médico que emite el diagnóstico simplista de "melancolía" respecto de la angustia de Sergio. A su vez, en medio de los argumentos que explican las causas y las razones de la angustia de Sergio, aparece entre comillas simples la voz de Sergio cuando él, en primera persona, explica cómo se manifiesta su enfermedad. Así, él mismo describe su propia angustia, en voz de Sofía, y además referida por la hermana menor, que se dirige al sobrino. Es un juego de espejos y también unas cajas chinas que, aunadas las particularidades de las historias que conforman el entramado, hacen de éste un cuento que exige estudiarse con detalle. De esta manera se llega a una de las partes medulares de la historia, que es la descripción de Sergio sobre su propia angustia:

Quiero encontrar una cosa tersa, armónica, por donde se deslice mi alma. No estos picos, estas heridas inútiles, este caer y levantar, más alto, más bajo, chueco, casi inmóvil y vertiginoso. $¿$ Te das cuenta? Siento que me caigo, que me tiran, por dentro, ¿entiendes?, me tiran de mí mismo y cuando voy cayendo no puedo respirar y grito, y no sé y siento que me acuchillan, con un cuchillo verdadero, aquí. Lo llevo clavado, y caigo y quedo inmóvil, sigo cayendo, inmóvil, cayendo, a ningún lugar, a nada. Lo peor es que no sé por qué sufro, por quién, qué hice para tener este gran remordimiento, que no es de algo que yo haya podido hacer, sino de otra cosa, y a veces me parece que lo voy 
a alcanzar, alcanzar a saber, a comprender por qué sufro de esta manera atroz, y cuando me empino y voy a alcanzar, y el pecho se me destiende, otra vez el golpe, la herida y vuelvo a caer, a caer. Esto se llama la angustia, estoy seguro. (179)

El cuento termina con la explicación del porqué Sofía no envió a Sergio a los médicos, y años después, cuando la hermana menor riega las plantas, lo hace lentamente para tratar de ignorar los gritos que deja escapar Sofía, la tercera que ha heredado el cuarto artesonado desde donde lanza sus gritos. Asimismo, aconseja al sobrino que, así como ella no desea comprender la locura, él tampoco intente comprenderla porque eso significaría el final de todo. Ella guarda la esperanza de que el sobrino, con la distancia, no se contagie al tratar de entender qué es y de dónde viene la enfermedad. Por eso ella tampoco quiere "entender lo que está fuera de nuestro pequeño orden” (182). En este sentido, el final del cuento resulta significativo porque pierde importancia la necesidad de explicar el mundo; es mejor, dentro de la lógica que establece la narradora, contemplarlo, en vez de tratar de comprenderlo y encontrar una razón de ser de las cosas. Lo anterior nos prepara para observar parte del fragmento final de la narradora:

Porque en realidad, explicar: ¿qué explica un loco?, ¿qué significa? Ruge, arrasa como el río, ahoga en sus aguas sin conciencia, arrastra las bestias mugientes en un sacrificio ancestral, alucinando, buscando en su correr la anulación, el descanso en un mar calmo que sea insensible a su llegada de furia y destrucción. ¿Qué mar?

Recoge su furia en las altas montañas, se llena de ira en las tormentas, en las nieves que nunca ve, que no son él, lo engendran viento y aguas, nace en barrancos y no tiene memoria de su nacimiento.

La paz de un estuario, de un majestuoso transcurrir hacia la profundidad estática. No balbucir más, no gritar, cantar por un momento antes de entrar en la inmensidad, en el eterno canto, en el ritmo acompasado y eterno. Ir perdiendo por las 
orillas el furor del origen, calmarse junto a los álamos callados, al lamer la tierra firme, y dejarla, apenas habiéndola tocado, para lograr el canto último, el susurro imponente del último momento, cuando el sol sea igual, el enemigo apaciguado del agua inmensa que se rige a sí misma.

Desconfiado, ceñudo consigo mismo, enemigo de todo, se entrega al fin, en paz y pequeño, reducido a su propia dimensión, a la muerte. Apenas aprendió a morir matando, sin razón, para alcanzar conciencia de sí mismo, en instantes apenas anteriores al desprenderse de su origen, de la historia que no recuerda, apaciblemente poderoso antes de entregarse, tranquilo y enorme, ensanchado, imponente ante el mar que no lo espera, que indiferente murmura y lo engulle sin piedad.

Aguas, simples aguas, turbias y limpias, resacas rencorosas y remansos traslúcidos, sol y viento, piedras mansas en el fondo, semejantes a rebaños, destrucción, crímenes, pozos quietos, riberas fértiles, flores, pájaros y tormentas, fuerza, furia y contemplación.

No salgas de tu ciudad. No vengas al país de los ríos. Nunca vuelvas a pensar en nosotros, ni en la locura. Y jamás se te ocurra dirigirnos un poco de amor. (182)

Lo que hace complejo al cuento no sólo es la profundidad que se logra al percibir aquellos secretos que intuitivamente uno va descubriendo, sino que la misma interpretación de la realidad expuesta por la narradora tiene diferentes dimensiones que resultan interesantes para el mejor entendimiento de esta narración. Si vemos que se asoma ese rasgo de intolerancia en el final, vemos también que, al igual que su hermana Sofía, la narradora ha tomado algunas decisiones. El reiterado equilibrio del que ella habla está a punto de romperse con la posible presencia del sobrino, quien no conoce "el río y sus avenidas; el sonar de las campanas; los gritos", y que no ha "estado tratando, siempre, de saber qué significan, juntas en el mundo, las cosas inexplicables, las cosas terribles, las cosas dulces" (173).

El río subterráneo es el río interno que surge como "el alarido", que en cierta forma es la antítesis de la metáfora bíblica de los ríos 
internos de agua viva. ${ }^{4}$ Éste, el que se narra en el cuento, es el río que describe la vida de Pablo, de Sergio, y ahora, también, de Sofía. La narradora sabe que está incluida en el destino al cual se refiere en el principio. En los últimos párrafos nos damos cuenta que las aguas inmensas (el mar) es la muerte, tal y como se entregaron Pablo y Sergio, así como en el futuro Sofía y ella. Por eso el final es prosa poética. Nótese que se puede leer exactamente imaginándonos el río y su fin en el delta, en el estuario, los esteros y finalmente el mar. Se puede repetir la lectura y pensamos en Pablo, en Sergio y en Sofía y se lee un conjunto de metáforas que describen el devenir de sus vidas, su locura y el camino final: "para lograr el canto último, el susurro imponente del último momento, cuando el sol sea igual, el enemigo apaciguado del agua inmensa que se rige a sí misma".

Esto va a prepararnos para un final desconcertante, en donde los hechos narrados pasan a una significación distinta debido a que, de manera sorpresiva, percibimos que quien nos ha narrado toda la historia empieza a mostrar, después de las descripciones poéticas del agua, del río, etcétera, una actitud diferente, imperativa, con un discurso que trastoca la delicadeza y la puntualización con la que se habían descrito los recuerdos y sus actos contemplativos sobre el río y su curso.

No debes venir, dice al sobrino, porque esto tiene que morir conmigo, no podemos darle continuidad porque "esto que sufrimos no es justo". Quédate en tu ciudad. Aquí, en el país de los ríos, está la locura, que es el río subterráneo que corre, tranquilo, apacible, inadvertido, cuyos "remansos traslúcidos" se convierten en "resacas rencorosas", "en furia y destrucción". Al igual que el río, la locura es la etapa previa, lenta, que irrumpe desbordándose, arrasando y destruyendo, hacia la muerte, que son las aguas profundas del mar, estáticas, donde deja de haber movimiento, donde todo es oscuridad. Dina

${ }^{4}$ Véanse los estudios que existen acerca de las referencias religiosas en la obra narrativa de Inés Arredondo, especialmente en su primer libro, La señal (Graciela Martínez-Zalce, Una poética de lo subterráneo: la narrativa de Inés Arredondo. México: Conaculta, 1996). 
Grijalva Monteverde menciona que, en este cuento, Inés Arredondo "logró captarla [la locura] en su estado más puro; en este relato parece condensar lo diseminado en otros de sus textos. Aquí ya no es el resultado de otra historia, de otra pasión, es la historia central, al tiempo que contiene en una dimensión simbólica la lucha de la escritura contra la angustia" (91-92).

En las palabras de la tía hacia el sobrino hay una intención que también es importante para entender el cuento. La enunciación (dicha, contada o escrita, en este caso) tiene una función terapéutica que alivia el dolor de la narradora. Es ese dolor que vive en "esa alma provinciana que todo lo pule". Por eso, dice, "soy la guardiana de lo prohibido", es decir, de la locura, y mi función es intentar que exista el equilibrio, así como fue terapéutica para Sofía y Sergio la construcción de la escalinata. Si bien el cuento no alude al acto de escritura como tal, estamos leyendo un texto que bien podría ser una carta escrita al sobrino con transcripciones de conversaciones de antaño entre Sofía, Sergio y ella misma en su infancia y primera juventud. Tiene un carácter confesional que recuerda al género epistolar.

La sorpresa es múltiple: el río es la vida, pero la vida desbordada es la locura y ésta termina en la muerte. Pero el misterio se intensifica en una gradación muy interesante: 1) una voz explicativa se transforma en 2) una voz poética que describe la naturaleza de manera metafórica, relacionada con la locura; y 3) termina en una voz imperativa que advierte a esa segunda persona a quien ha dirigido toda la narración que no venga nunca, que no salga de su ciudad, que no vaya al país de los ríos y aún, que nunca vuelva a pensar en ellos (es una orden), ni en la locura (te advierto que tú sigues: parte de la estructura profunda de ese final). Y sobre todo, quizá las palabras más intensas, que "jamás se te ocurra dirigirnos un poco de amor". Es decir, ni te atrevas a querernos, porque ésa va a ser tu perdición, porque sólo al negar nuestra existencia podrás permanecer en tu sano juicio.

El río es la vida, pero dentro de este mundo ficcional, la vida también es creatividad, el éxtasis, contemplación, y también, por otra parte, la locura. Es lo que no se explica, simplemente existe. Por eso la frase "Porque en realidad, explicar: ¿qué explica un loco?, ¿qué significa? Ruge, arrasa como el río, ahoga en sus aguas sin conciencia, 
arrastra las bestias mugientes en un sacrificio ancestral, alucinando, buscando en su correr la anulación, el descanso en un mar calmo que sea insensible a su llegada de furia y destrucción. ¿Qué mar?” (182). A la muerte le precede la vida, el origen, los inicios, por eso es el río "Recoge su furia en las altas montañas, se llena de ira en las tormentas, en las nieves que nunca ve, que no son él, lo engendran viento y aguas, nace en barrancos y no tiene memoria de su nacimiento".

"Río subterráneo" es una escritura que tiene diferentes momentos e intenciones que la van transformando hacia una realidad poética, epifánica, que estará presente en los últimos párrafos. El acto creativo salva, por el momento, a la narradora. El misterio de la vida, en el cuento, y por lo tanto parte de la poética de esta escritura, reside en una interesante relación entre el lenguaje y la contemplación como instrumentos para crear el mundo. De esta manera, al encontrarse el equilibrio mediante la contemplación vislumbramos parte de esa verdad ${ }^{5}$ a la que Inés se refiere en su autobiografía, presentimos una verdad (filosófica) ${ }^{6}$ al final del cuento, que consiste en el misterio que siempre ha rodeado el lenguaje poético, un misterio que solamente nos arroja ciertas luces ante la enigmática significación de la existencia.

Sobre el juego de la escritura, dice Pál Réz que: "El hombre que juega hace llevadera la insoportable existencia complicando y simplificando al mundo en un juego" (22). Ella misma se cura al jugar con el lenguaje. Si ella ha permanecido, hasta el momento, lúcida, es porque vive el acto de creación. Así como Sofía y Sergio disfrutaron la belleza del acto creativo al construir la escalinata y los cuartos artesonados, la narradora es feliz cuando reproduce la belleza en el acto de enunciación de la realidad y de los hechos, y se conduce hacia una

${ }^{5}$ Huberto Batis en la "Presentación" a Mariana, publicado por la UNAM en la colección Material de Lectura, se refiere a esa verdad filosófica como "manifestación apofántica" (3).

${ }^{6}$ Arredondo, Inés, "La verdad o el presentimiento de la verdad". Obras completas México: Siglo XXI/Difocur, 1989. 
plenitud que compartimos en la lectura del lenguaje poético en donde aparecen el agua, el río, el mar. Pero ese aliento de asombro se corta cuando pasa de la epifanía a algo asombroso por sorprendente y porque termina siendo una realidad apabullante: el cambio drástico del acto contemplativo estético a un resquemor parecido a la ira que se advierte en unas órdenes que parecen más un conjunto de amenazas. Es el nuevo aliento que se impone en una advertencia fatal: "No salgas de tu ciudad. No vengas al país de los ríos. ${ }^{7}$ Nunca vuelvas a pensar en nosotros, ni en la locura". Pero sobre todo esta última sentencia: "Y jamás se te ocurra dirigirnos un poco de amor". Al haber alcanzado el equilibrio, abruptamente se pierde porque la fiera ya está al acecho, a punto de atacar.

El cuento ofrece secretos cuyos fragmentos sólo podemos intentar descifrar, intuir, pero son fragmentos de una realidad muy compleja; misterios que encierra el arte. Paradójicamente, escribir sobre

${ }^{7}$ La mayoría de los cuentos de Inés Arredondo recrean el lugar donde vivió parte de su infancia, y que en su narrativa adquiere ciertos rasgos míticos. Eldorado, Sinaloa, es el pueblo que se fundó originalmente con los trabajadores de la hacienda azucarera establecida ahí en el siglo XIX, al margen del río San Lorenzo. A Sinaloa se le conoce también como "el estado de los once ríos". Si bien en este cuento no hay una clara identificación con un espacio extraficcional, sabemos que buena parte de sus cuentos están situados en lugares específicos; como por ejemplo el Estero de Dautillos (Altata) en "Mariana", así como un identificable Eldorado, en donde están inspirados la mayoría de sus cuentos, no obstante la libre transformación del espacio que Arredondo maneja a su antojo en cada cuento. "El San Lorenzo", menciona quien narra en "Las palabras silenciosas", el río que alimenta el huerto y las verduras de Manuel. Si bien es difícil identificar un lugar preciso para "Río subterráneo", hay un fragmento que dice que los revolucionarios llegaron "por el camino de la Bebelama”. En efecto, situándonos en El Dorado, río arriba en el río San Lorenzo se encuentra (hacia el noreste) el pequeño poblado de La Bebelama. Por ejemplo en "La Sunamita" se menciona Mazatlán, cuando el tío Apolonio le regala el collar: "-Mira, este collar se lo regalé a tu tía cuando cumplimos diez años de casados, lo compré en Mazatlán a un joyero polaco que me contó no sé qué cuentos de princesas austriacas y me lo vendió bien caro. Lo traje escondido en la funda de mi pistola y no dormí un minuto en la diligencia por miedo a que me lo robaran..." (133). 
la locura es escribir sobre la desarticulación del mundo, y escribir sobre la muerte es sobre el final de todo; el silencio; las aguas en donde el río muere ante su propia inmensidad. La paradoja consiste en que el acto de escritura es un acto de articulación de un mundo, y también, la antítesis del silencio absoluto. "Río subterráneo" seguirá siendo un cuento que continúe develando sus misterios. Pertenece a ese tipo de textos que son "inagotables", pues cada lectura arroja nuevas luces que permiten apenas asomarse a su complejidad y profundidad textuales. Por eso queda la sensación de que cada lectura resulta insuficiente, porque cada vez nos conduce a nuevas preguntas. Concuerdo con Dina Grijalva cuando menciona que en este cuento "Inés Arredondo logra no sólo asomarse a los bordes del abismo de las pulsiones y terrores primigenios, logra por momentos penetrar en esos abismos y emerger mediante la belleza. El horror y lo siniestro son asidos por un discurso que, sin eludirlos, busca hacer triunfar lo estético y lo bello sobre lo monstruoso" (102).

Incluso los lectores podemos vernos involucrados irónicamente dentro de este juego de escritura, pues ante las estrategias discursivas utilizadas -cuyos efectos podrían acercarnos más hacia la subjetividad del receptor (o sea, del sobrino) - nosotros mismos caeríamos en el error de intentar explicar un mundo cuya lógica de entrada es inexplicable con las herramientas interpretativas de la razón. Semejante asalto a la razón conduce a elaborarnos preguntas un tanto lúdicas: ¿puede, realmente, la narradora de "Río subterráneo" tendernos una trampa? ¿No será que al tratar de explicar su escritura, nos veremos en la misma dinámica de explicación y entendimiento en la que se vieron inmersos Sergio y Sofía al tratar de comprender la locura de Pablo? Ellos entendieron el arte, lo crearon y contemplaron, pero al mismo tiempo intentaron explicarse los intrincados caminos de la locura. La narradora, a su vez, aprendió el arte de narrar de su hermana, y ella tiene un destino. Cuidado, mucho cuidado: hay que recordar que: "Sergio enloqueció como él [como Pablo] cuando lo vio, cuando quiso entenderlo. No es que tuviera piedad, lástima tonta, solamente quería entender. Pero es seguramente ése el camino justo que la locura misma ha trazado para sus verdaderos elegidos" (181). 
Si el río es la metáfora de la vida, y si en ella misma la locura irrumpe como las corrientes traicioneras y caprichosas, entonces hay una relación equivalente entre el acto de la creación como una antítesis de la locura, aunque estrechamente relacionada de manera que se puede observar una relación de inmanencia entre creación y locura. Los personajes optan por la creación y la lucidez, aunque tienen un destino que ellos no han escogido y cuya aparición no pueden controlar. Si articulamos un mundo nuevo y exclusivo a través de los medios de la creación artística, entre ellos el acto verbal a través del lenguaje poético, del juego (creativo) que reacomoda el caos, funciona éste, entonces, como el acto paliativo que interrumpe el caos, la desorganización del mundo, la desarticulación del mundo que existe y sólo existe mediante la locura; la pérdida del juicio: el desorden de las cosas a las que conlleva la locura.

En este sentido, dentro de la lógica que impera en el cuento vivimos momentáneamente a través de lo que conocemos como plenitud. Y en eso consiste la aparición de las musas. Sólo nosotros mismos somos responsables de invocarlas. Lo demás es existencia tormentosa que sólo nos acerca cada vez más hacia el fin y nos recuerda la fugacidad de la vida y la terrible inmensidad de la inexistencia, de la muerte: el final del camino, donde el sol ya no es un elemento a vencer. La vida es terrible; es verdad, es un enunciado con carácter apofántico, pero sólo esos actos de lucidez y plenitud son los que nos hacen estar convencidos de que vale la pena vivir.

\section{Bibliografía}

Albarrán, Claudia. Luna menguante. Vida y obra de Inés Arredondo. México: Juan Pablos, 2002.

Arredondo, Inés. Cuentos completos. México: FCE, 2010.

Hernández Escobar, María Cristina. "A la izquierda de la razón: acercamiento a lo siniestro en Inés Arredondo y Clarice Lispector”. Tesis de Maestría en Literatura Comparada. México: UNAM, 2010. Grijalva Monteverde, María Dina. Eldorado: evocación y mito en la narrativa de Inés Arredondo. Culiacán: Forca Noroeste, 2011. 
Kosztolányi, Dezsö. La visita y otros cuentos. Tr. Irma Agüero. Selección Vera Székacs. Bogotá: Norma, 1999.

Osuna Osuna, Gabriel. "La representación del Otro en 'Las palabras silenciosas' de Inés Arredondo". Los divertimentos de las musas. Ensayos sobre escritoras mexicanas e hispanoamericanas. Comp. y ed. Alma Leticia Martínez Figueroa. Hermosillo: Universidad de Sonora, 2009. 177-95.

Réz, Pál. "Dezsö Kostolányi”. (Kostolányi 924).

Tornero, Angélica. El mal en la narrativa de Inés Arredondo. México: Universidad Autónoma del Estado de Morelos/Juan Pablos, 2008. 